\title{
A Base orientadora da ação para a leitura compreensiva de textos de Ciências: um estudo com estudantes de Pedagogia
}

The Orientation for Activity to Comprehensive Reading of Science Texts: A Study with Students of Pedagogy

\author{
Alessandro Augusto Barros Façanha \\ Micarla Silva de Azevedo²
}

\section{Resumo}

Este estudo traz os resultados de uma investigação sobre a orientação da ação utilizada por estudantes de pedagogia para ler textos de conteúdo das ciências a fim de relacionar a base orientadora da ação com os conhecimentos profissionais para ensinar ciências. Tem como marco teórico a teoria da atividade de Leontiev e teoria da formação das ações mentais e dos conceitos de P. Ya. Galperin, como proposta metodológica realizou um estudo exploratório da temática a partir de um esboço do experimento formativo com a aplicação de uma prova pedagógica. Os resultados demonstram a caracterização da orientação dos futuros professores de ciências a partir das quais é possível compreender as dimensões cognoscitivas dos estudantes em relação à leitura compreensiva sendo possível constatar preliminarmente que a orientação da ação da maioria dos estudantes investigados não corresponde ao que se espera do ideal em relação ao sistema estrutural e operacional da ação.

Palavras-chave: orientação da ação; leitura compreensiva; ensino de ciências.

\section{Abstract}

This study brings the results of an investigation into the orientation of the activity used by students of pedagogy to read texts of content of the sciences in order to relate the basis of action with the professional knowledge to teach science. It has as theoretical framework the theory of Leontiev's activity and theory of the formation of mental actions and the concepts of P. Ya. Galperin, as a methodological proposal carried out an exploratory study of the thematic from a sketch of the training experiment with the application of a pedagogical test. The results demonstrate the characterization of the orientation of the future science teachers from which it is possible to understand the cognitive dimensions of the students in relation to the comprehension reading. It is possible to establish preliminarily that the orientation of the action of the majority of the investigated students does not correspond to what is expected from the ideal in relation to the structural and operational system of action.

Keywords: action orientation; comprehensive reading; science teaching.

\footnotetext{
1 Universidade Federal do Rio Grande do Norte | abfacanha@gmail.com

2 Universidade Federal do Rio Grande do Norte | silvamicarla14@gmail.com
} 


\section{A orientação da ação de P. Ya. Galperin e suas intersecções no campo da docência: um diálogo com a didática desenvolvimental}

A Teoria da Formação Planejada das Ações Mentais e dos Conceitos postulada por P. Ya. Galperin se caracteriza como um ponto de inflexão no contexto da psicologia soviética no que tange ao estudo do desenvolvimento psíquico associado processo cognoscitivo. Em continuidade aos estudos desenvolvidos no âmbito da teoria da atividade de A. N. Leontiev e da formação das funções psicológicas superiores de L. S. Vygotski, Galperin inaugura o que se pode chamar de um marco epistemológico na compreensão do processo de internalização da teoria histórico-cultural a partir da interseção entre a ação, a consciência e a assimilação de conceitos por meio de atividades planejadas que mediatizam a formação das ações mentais do plano interpsíquico para o plano intrapsíquico.

Dessa forma, o cerne de suas ideias - a formação das ações mentais - se ancora epistemologicamente no contexto da teoria da atividade e no conceito de internalização, oriundos do enfoque histórico-cultural do psiquismo, porém com o intuito de dirimir lacunas acerca do entendimento da formação das representações mentais relacionadas às denominadas funções psicológicas superiores tornando possível compreender, como explicam Nuñez e Ramalho (2015), que através de atividades planejadas se desenvolvem processos psíquicos que confluem para a formação de processos mentais decorrentes da atividade consciente que determinam a internalização de conceitos.

Nesse sentido tem como núcleo a relação dialética do sujeito com a realidade a partir de uma perspectiva histórico-cultural do desenvolvimento, com ênfase nos aspectos sociais, culturais e nos mecanismos de mediatização semiótica que estabelecem vínculos entre o mundo exterior e as funções psíquicas internas inerentes à aprendizagem e ao processo de desenvolvimento dos sujeitos a partir da atividade, a qual, como destaca Leontiev (1978), se constitui como elemento formador de um sujeito psicológico que interliga os aspectos cognitivos ou conscientes com os atributos da personalidade propiciando o desenvolvimento da subjetividade a partir da apropriação da realidade objetiva.

Nesta perspectiva a atividade passa a ser defendida como a unidade central e estruturante na orientação do desenvolvimento do indivíduo de modo que a atividade psíquica interna é compreendida como a representação da uma atividade externa e materializada, fundando o princípio essencial da psicologia histórico cultural que tem na psique sua unidade (Leontiev, 1978).

Caracterizando a atividade como princípio deste processo de desenvolvimento psíquico Galperin (1979), destaca que as ações humanas precisam ser consideradas a partir de sua estrutura funcional que consistem em subsistemas de orientação, execução e controle, onde, a orientação constitui a representação que o sujeito tem da ação e as condições de sua realização, a execução consiste na transformação do objeto da ação e o controle representa o acompanhamento da ação onde se avalia o processo.

Ratificando essas concepções teóricas Talízina (1998), destaca que no contexto da teoria da atividade, as etapas funcionais da ação - a base orientadora, a execução e o controle - apesar de caracterizadas de forma individualizada, se desenvolvem de forma inter- 
relacionada e integradas a fim de promoverem um conjunto de condições concretas necessárias para a internalização dos conceitos ou habilidades e seu consequente processo de aprendizagem.

Assim a ação se configura como um processo não linear dos seus subsistemas funcionais onde a partir do princípio da totalidade marxista e da intersecção de suas etapas se constitui o processo de desenvolvimento cognoscitivo. No entanto, em função da estrutura da psique e do núcleo do planejamento como objeto das ações conscientes há um destaque para a etapa orientadora da ação, pois, considerando a base orientadora no percurso do desenvolvimento humano no sentido de sua aprendizagem, como percebe Galperin (2001), a orientação da ação representa a etapa norteadora dessas ações que se materializa a partir de uma estrutura funcional e operacional da atividade a qual possibilita a formação de novos conhecimentos ou a incorporação de novas qualidades ao conhecimento possuído se configurando como um elo entre a teoria e a prática no sentido de significar uma intersecção entre o objeto e a ação em função de sua internalização:

En este sentido, las condiciones concretas de la acción aparecen como eslabón objetivo que une la teoría y la práctica, la fundamentación científica para pasar de los conocimientos teóricos (sobre el objeto y la acción) a su aplicación para la solución de las tareas prácticas. (...) Las condiciones hacia las que se orienta el sujeto en el cumplimiento de una acción, constituyen la base de la orientación de esta acción (GALPERIN, 2001).

Dessa maneira, em termos operacionais, como define Talizina (1988), a orientação é um sistema de condições concretas necessárias para o êxito do cumprimento da ação, utilizadas pelo sujeito a fim de assegurar a execução para a transformação do objeto. No contexto da sistematização da ação Galperin ressalta que:

A parte orientadora é a instância diretiva e, precisamente, no fundamental, depende dela a qualidade da execução. Se elaboramos um conjunto de situações em que se deva aplicar essa ação conforme o plano de ensino, essas situações ditarão um conjunto de exigências para a ação que se forma e, juntamente com elas, um grupo de propriedades que respondem a essas exigências e estão sujeitas à formação (GALPERIN, 1987).

Nesse sentido, a base orientadora se constitui como um modelo estruturante da ação que reflete os componentes de um conceito/habilidade e que confere uma representação sistematizada da ação através de um caráter epistemológico na formação das habilidades, pois encerra em si os aspectos teóricos da assimilação não representando somente uma estrutura meramente técnica ou reprodutora de operações que se constitui como um modelo da atividade ou que reflete um sistema estrutural e funcional do objeto a ser internalizado, mas ao contrário, como expõe Talízina (2000), a base orientadora explicita um sistema de condições para a realização de uma ação com a máxima eficiência e mínimos erros em função de integrar a essência da ação a ser executada que para além dessa natureza, também expressa a orientação das necessidades e motivações sobre as quais o sujeito dá sentido à execução das ações e a assimilação dos conteúdos derivados desta ação. 
Dessa maneira, a base orientadora pode ser compreendida tanto em seus termos conceituais que expressam a orientação da ação como um conjunto de condições essenciais e necessárias para a execução de uma ação, cujo produto em termos da aprendizagem é a formação das ações mentais e suas representações psíquicas de um dado objeto da realidade (conceito/habilidade), bem como em seus termos psicológicos ou volitivos, conferindo motivação para sua execução tornando o sujeito consciente de sua ação e garantindo assim a satisfação de suas necessidades.

Daí reside sua importância epistemológica e mesmo heurística no que diz respeito ao campo cognoscitivo da psicologia da aprendizagem, pois a orientação da ação no contexto da formação planejada das ações mentais e dos conceitos adquire ao longo da produção do conhecimento, um arcabouço didático que pode ser incorporado no âmbito da atividade docente através de um status de sistema didático da psicologia desenvolvimental, isto porque, como explicam Nuñez e Oliveira (2015), os pressupostos da teoria de Galperin além de contribuírem para a compreensão do processo do desenvolvimento interpsíquico da formação das ações mentais e dos conceitos, aprimora o entendimento das ações em função de seu planejamento cognoscitivo, podendo assim, servir de subsidio na prática docente cotidiana em termos do planejamento docente e da elaboração de constructos didáticos para a formação de professores para o desenvolvimento de conceitos/habilidades em sala de aula.

Na perspectiva da didática e do planejamento para o ensino, como demonstram as evidências e as pesquisas correlacionadas, amplia a percepção de um modelo de formação inserido não exclusivamente no âmbito do psiquismo e da aprendizagem conceitual, mas no contexto do desenvolvimento das habilidades a partir de seu modelo orientador, pois, como explica Bassan (2012), a função orientadora tem como foco a apresentação do método com seus objetivos e especificidades, a função executiva produz o estado e ato de efetivação da ação com base no método elaborado onde ocorre a transformação do objeto em estudo e a função de controle com a responsabilidade de introduzir correções na ação elaborada.

É neste sentido que se embasa o contexto desta investigação que teve por objetivo geral compreender o conhecimento profissional de estudantes de Pedagogia sobre a orientação da ação para leitura compreensiva de textos de conteúdo científico e sua utilização como recurso didático para ensinar ciências nos anos iniciais da educação básica. Neste contexto se formularam as seguintes questões de pesquisa:

a. O que é a orientação da ação para leitura compreensiva de textos científicos em relação ao modelo do objeto (conceito) e ao modelo da ação (como se realiza)?

b. Como você se orienta para realizar uma leitura compreensiva de um texto de conteúdo de ciências?

Como referência para a orientação da ação para leitura compreensiva de textos de conteúdo científico foi utilizado um modelo de base orientadora completa da ação validada, cujo detalhamento é pormenorizado no contexto metodológico deste estudo.

Em conformidade com as diretrizes curriculares para os cursos de pedagogia em vigência, espera-se que estudantes com esse nível de formação em curso tenham adquirido habilidades que os capacite a: investigações sobre processos educativos; avaliação, criação e uso de textos, materiais didáticos, procedimentos e processos de aprendizagem que contemplem a diversidade social e cultural da sociedade brasileira; estudo, análise e avaliação 
de teorias da educação, a fim de elaborar propostas educacionais consistentes e inovadoras (BRASIL, 2006).

\section{A leitura compreensiva na formação do pedagogo e como habilidade linguístico-cognitiva para o ensino das ciências}

Analisando o contexto da leitura ao longo do tempo observa que se trata de um conceito em perene transição e ressignificações que acompanha a dinâmica social da comunicação no sentido de uma evolução conceitual a medida que o mundo se transforma. Em uma dimensão cronológica, no intervalo de duas décadas, a leitura sofre uma intensa variação semântica que vai da decodificação literal do texto ao plano da intertextualidade e da hipermodalidade textual com a mesma velocidade da era das informações instantâneas e da volatilidade da linguagem em tempos de fluidez exagerada.

$\mathrm{Na}$ atualidade, com o advento do hipertexto, das multifuncionalidades da linguagem e com a importância do caráter contextual na compreensão do texto, percebe-se a aproximação do discurso às múltiplas funções de interpretação semiótica onde a leitura adquire como ressalta Koch (2018), uma concepção de representação do sujeito enquanto expressão do pensamento ativo, interativo e em pleno processamento de sentidos onde o que mais importa são os fluxos de linguagens ao invés das funções de simples decodificação da informação, em outros termos, o texto se configura como uma prática social.

Neste sentido a leitura coincide com seu contexto social, político e em plena busca de autonomia para os sujeitos em função da expressão como recurso de poder e inserção que a torna, no campo da educação, uma habilidade em intenso desequilíbrio em função das adequações relativas ao campo semiótico que ecoam na escola, na formação dos professores, no currículo e nas demandas educacionais para o novo milênio que refletem sobre a leitura suas demandas sociais. Como esclarece Dos Santos et al (2006), no contexto da escola a leitura passa a se constituir para além da importante ferramenta de aprendizagem, uma peça de extrema importância no papel social dos indivíduos e um elo de inserção cultural e social.

No epicentro dessa dinâmica se encontra a formação de professores e os agentes diretos do processo de formação de leitores que são os pedagogos e os futuros profissionais da pedagogia, pois, em consonância com as diretrizes curriculares e os demais normativos que ditam sobre a obrigatoriedade da formação leitora, são estes os profissionais responsáveis diretamente pelo que diz o art. 32 da Lei 9394/96 que estabelece a obrigação da formação leitora e sua compreensão como uma habilidade para o domínio também da escrita, do cálculo e da intersecção com demais áreas do conhecimento (Brasil, 1996).

Assim, com destaque a essa ebulição em torno da habilidade leitora vem a reboque uma série de necessidades de formação desses pedagogos a fim de acompanhar esse processo de evolução, que além de estabelecer a responsabilidade do processo de formação leitora aos profissionais da pedagogia, exige que se desenvolva a habilidade da leitura para além do escopo da alfabetização e letramento passando a interpretá-la em um contexto multidisciplinar integrando-a as demais áreas do conhecimento como, por exemplo, o cálculo e ao aprendizado dos demais conteúdos demonstrando a intenção de se inserir a leitura como uma habilidade nuclear do aprendizado. 
Nesse sentido o caráter compreensivo da leitura, para além da formação leitora em si, se reflete como uma condição necessária ao processo interdisciplinar que envolve a formação de habilidades linguísticas inseridas também na educação científica. Desta maneira, compreendendo a leitura em um campo da habilidade como o fazem Jorba, Gómez e Prat (2000) e Sanmartí (2007), se constitui, portanto no rol das habilidades linguístico-cognitivas imprescindíveis ao ensino e produção das ciências a partir de um contexto compreensivo e comunicador.

Em consonância a isto Sanmartí (2007), afirma que a leitura se configura como parte integrante no universo do ensino, do aprendizado e da produção científica, pois permite aos alunos aprenderem as exigências do uso da linguagem científica, caracterizado, dentre outros, pela precisão no uso do léxico, pela compreensão leitora e o uso adequado das habilidades linguísticas. Ampliando esse enfoque, Jorba, Gómez e Prat (2000), explica que para se pensar em um conceito amplo de aprendizado e sua internalização na perspectiva cognitiva, implica compreender as habilidades linguísticas, com especial atenção para a leitura, não só como subsidio ao aprendizado, mas, sobretudo, como sedimento para o desenvolvimento sóciocognitivo e psico-cognitivo dos sujeitos.

Neste sentido a leitura também se alinha ao enfoque epistemológico da matriz históricocultural na qual se insere a perspectiva deste estudo, uma vez que a orientação da ação para a leitura se promulga a partir de sua natureza psíquica e de desenvolvimento da linguagem, da aquisição semiótica e das ações mentais em torno da habilidade psicológica da leitura como defendem os postulados de Vygotski acerca da linguagem, onde se observa que:

El lenguaje es ante todo um medio de comunicación social, um medio de expresión y comprensión. Generalmente, en el análisis por decomposición en elementos, esta función del lenguaje también se separaba de la intelectual y ambas eran atribuidas al lenguaje, como si dijéramos, paralela e indepiendiente una de la otra. Se sabe que el lenguaje combina la función comunicativa con la de pensar, pero no se ha investigado, ni se investiga que relación que existe entre ambas funciones, qué condiciona su coincidencia em el lenguaje, cómo de desarollan, ni cómo están unidas estruturalmente entre sí. No obstante, el significado de la palabra es unidad de ambas funciones del lenguaje em la misma medida que es unidade del pensamento (Vygotski, 1993, p. 132).

Dessa maneira, se ratifica a leitura como habilidade linguístico-cognitiva inerente ao desenvolvimento psíquico que no sentido da orientação da ação se constitui como um reflexo da atividade consciente do sujeito e um processo de formação das ações mentais, além de se estabelecer, no âmbito da educação científica como uma habilidade imprescindível ao espectro do ensino das ciências, a medida que o desenvolvimento da habilidade leitora ocorre em virtude de um desenvolvimento que intersecciona atributos sociais e culturais assim como psíquicos e reguladores da aprendizagem, presente inclusive nas matrizes de referência dos exames de avaliação nacionais e internacionais ligados inclusive ao aprendizado das ciências, como por exemplo no Programa Internacional de Avaliação de Estudantes (PISA), ratificando assim, como expressam Jorge, Bargalló e Puig (2006), que a habilidade da leitura confere uma rede de relações com as demais áreas do conhecimento, em especial as Ciências, pois 
propicia uma compreensão em múltiplos níveis e funções de leitura e suporte de compreensão - literal, inferencial, avaliativa e criativa.

(...) reflexionar sobre el contenido de un texto exige que el lector conecte la información encontrada en un escrito con el conocimiento que surge de otras fuentes. Los lectores, también, deben evaluar las afirmaciones que se hacen en el texto contra su propio conocimiento del mundo (...) Los lectores deben ser capaces de desarrollar una comprensión de lo que se dice y se pretende decir en un texto y deben verificar esa representación mental contra lo que conocen y en lo que creen sobre la base de, ya sea, información previa o de información encontrada en otros textos. Los lectores deben emplear evidencia de apoyo que se encuentre dentro del texto y contrastarla con otras fuentes de información, al emplear tanto el conocimiento general como el específico y la capacidad de razonar de manera abstracta (OCDE, 2000, p. 32).

Portanto, a leitura é uma habilidade linguístico-cognitiva de superlativa importância na formação dos futuros professores, sobretudo os responsáveis pelo processo de educação científica, pois é incongruente se pensar na aprendizagem das ciências sem o desenvolvimento da habilidade leitora, pois, como justifica Márquez (2005), os estudantes aprendem ciências enquanto aprendem a descrever, justificar, argumentar, definir e escrever textos científicos, para os quais necessitam compreender o texto, o contexto e dar sentido à própria ciência, assim, separar o ensino das formas de um determinado texto e de seu conteúdo, impossibilita a aprendizagem de um ou de outro.

Nesse sentido, se coadunando com as questões propostas para este estudo surgem as indagações: os futuros professores de ciências nos anos iniciais desenvolveram ao longo de sua formação a habilidade da leitura compreensiva para lerem textos de ciências? O conhecimento dos pedagogos sobre a habilidade da leitura compreensiva para ler textos de ciências os possibilita executar essa ação em sala de aula? A orientação da ação para ler textos de ciências é uma premissa observada na formação desses professores?

Como se percebe, inclusive corroborando com as ideias expostas por Carvalho e GilPérez (2003), conhecer o conteúdo a ser ensinado é uma premissa estrutural para o ensino das ciências e ampliando esse pressuposto, a partir das argumentações expostas no contexto das habilidades linguístico-cognitivas, é indispensável ao futuro professor das ciências não apenas compreender essa necessidade, mas, sobretudo ser capaz de realizá-la em sua profissão. Para tanto é necessário não só a inserção dessas habilidades na formação desses professores, mas um direcionamento sobre as bases epistemológicas e metodológicas sobre tais concepções, como por exemplo, a compreensão acerca de uma base orientadora que promova o desenvolvimento dessas habilidades como conhecimento profissional da atividade docente. 


\section{A habilidade da leitura compreensiva no contexto da orientação da ação: referências para a atividade docente e o ensino das ciências}

Conforme caracterizado anteriormente, o ato de ler se reformula a medida que a sociedade se transforma, pois assim como outras categorias de natureza social, a leitura se ressignifica de acordo com as mudanças de paradigma, assim na atualidade a leitura não pode ser encarada como uma ação meramente decodificadora e literal, como define Koch e Elias (2006), a leitura se expressa como uma construção de sentidos por meio da mobilização de contextos a partir das ações mobilizadas por um texto.

Nesse aspecto ler compreensivamente enseja conforme argumenta Cassany $(2006,2010)$, a compreensão transliteral a partir da incorporação do contexto do discurso no sentido de extrair do texto suas possibilidades inferenciais a fim de proporcionar tomada de decisões e atuação do sujeito em seu meio social a partir de uma informação expressa.

No caso específico de textos de conteúdo científico, incorporando o conceito de habilidades linguístico-cognitivas, a leitura compreensiva é significativo o conceito expresso por Sanmartí (2011), segundo o qual:

Leer forma parte de la actividad científica y también de la actividad científica escolar. La lectura es, pues, una parte constitutiva de la génesis del conocimiento científico y tiene valor y sentido em sí misma, ya que posibilita ir más Allá de ló que se lee y generar nuevos saberes. Del mismo modo, em la escuela la lectura es un componente importante de la actividad científica escolar. Posibilita plantearse preguntas y acceder de las que se generan desde el llamado "sentido comum" (Sanmartí, 2011. p.3)

Assim, de acordo com o conceito norteador deste estudo, a leitura compreensiva encerra em si uma base orientadora da ação que de acordo com o conceito de orientação da ação de P. Ya. Galperin se constitui de um modelo do objeto e de um modelo da ação que consistem das invariantes conceitual e operacional sobre a leitura compreensiva, que no caso específico da base orientadora para ler textos de conteúdo científico apresenta um sistema de orientação validado pela comunidade científica e expresso na pesquisa de Victor e Nuñez (2015), os quais estabelecem a base orientadora para leitura compreensiva de textos de caráter científico na química a partir da caracterização das invariantes conceituais e operacionais que em conjunto se caracterizam pelo esquema da base orientadora completa da ação (EBOCA), que segundo Nuñez e Ramalho (2016), fornece aos estudantes uma ferramenta cultural para a generalização teórica, que permite a compreensão de um conjunto de situações ou de um dado domínio, sendo, portanto, uma condição para a formação de conceitos, de ações mentais e de habilidades com alta possibilidade de transferência da aprendizagem, se caracterizando por condensar a essência das características necessárias à orientação de referência. Para o foco desta investigação se utilizou como este referencial uma adaptação do EBOCA elaborado por Victor e Nuñez (2015) caracterizado no quadro abaixo: 
Quadro I. Modelo do EBOCA para leitura compreensiva de textos de Ciências

\begin{tabular}{|c|c|}
\hline $\begin{array}{l}\text { Modelo do Objeto } \\
\text { (O que é ler compreensivamente um } \\
\text { texto de Ciências?) }\end{array}$ & $\begin{array}{c}\text { Modelo da ação } \\
\text { (Sistema de operações: como se faz a leitura } \\
\text { compreensiva de um texto de conteúdo científico?) }\end{array}$ \\
\hline $\begin{array}{l}\text { Leitura que propicia o processo de } \\
\text { transformação da informação em } \\
\text { conhecimento a partir do domínio das } \\
\text { habilidades baseadas no conhecimento da } \\
\text { Ciência a fim de assimilar os } \\
\text { conhecimentos para aprender e satisfazer } \\
\text { necessidades do cotidiano relacionadas ao } \\
\text { conteúdo do texto }\end{array}$ & $\begin{array}{l}\text { - Ler o título e fazer inferências antecipando } \\
\text { possíveis intencionalidades do autor; } \\
\text { - Identificar o autor e o contexto da produção; } \\
\text { O1: Levantar hipóteses a partir das informações; } \\
\text { O2: Solucionar dificuldades em relação ao texto } \\
\text { (vocabulário e conceitos científicos desconhecidos); } \\
\text { O3: Relacionar as informações aos conhecimentos } \\
\text { prévios confirmando ou não as hipóteses } \\
\text { levantadas; } \\
\text { O4: Elaborar estratégias metacognitivas para a } \\
\text { compreensão das informações científicas: formular } \\
\text { perguntas, destacar informações do texto; } \\
\text { O5: Fazer inferências a partir das informações do } \\
\text { texto; } \\
\text { O6: Estabelecer conexões entre os parágrafos do } \\
\text { texto para compreender a lógica do assunto; } \\
\text { O7: Interpretar o texto a partir do conhecimento } \\
\text { científico exigido e valido; } \\
\text { O8: Elaborar uma síntese das informações; } \\
\text { O9: Avaliar a compreensão e aplicações das } \\
\text { informações do texto no cotidiano. }\end{array}$ \\
\hline
\end{tabular}

(Fonte: Victor e Nuñez, 2015. Adaptado para o estudo, pelos autores).

Como se observa o modelo do objeto se configura como um referencial conceitual da habilidade e o modelo da ação um sistema operacional de nove operações (01 - O9), as quais em conjunto estabelecem o modelo da ação de referência para se realizar uma ação completa de leitura compreensiva para textos de conteúdo científico.

Neste sentido, a orientação da ação se configura como um conhecimento profissional desejável para o exercício da profissão docente contribuindo para a profissionalização docente no sentido de sua profissionalidade, uma vez que amplifica como defendem Nuñez e Ramalho (2008), para a relaboração da dimensão de conhecimentos e saberes necessários à atividade profissional, ampliando as competências necessárias ao desempenho da profissão docente, visto que de acordo com as justificativas postuladas na atualidade como reiteram Sanmartí (2007), Marbá e Márquez (2005), Bargalló e Prat (2005), a habilidade linguísticocognitiva da leitura é essencial ao ensino das ciências, pois dentre outras funções, como o próprio processo compreensivo, a leitura possibilita ao estudante nas aulas de ciências, a 
formulação de hipóteses para solução de problemas, a construção de sentidos, a reflexão sobre temáticas do cotidiano e a elaboração do pensamento científico.

Nesta perspectiva se argumenta neste estudo que para se estabelecer uma prática docente efetiva e articulada com as premissas de um ensino de ciências contextualizado e voltado para a inserção da leitura como instrumento de aprendizagem e inserida inclusive no contingente formativo elencado pelas diretrizes curriculares da formação dos pedagogos onde se está prevista a inserção da educação científica em função da decodificação e utilização de códigos e diferentes linguagens no trabalho didático com conteúdos de Ciências (BRASIL, 2006, p. 3), é fundamental que a formação do futuro pedagogo contemple os aspectos relativos à orientação da ação para a leitura compreensiva de textos de conteúdo científico em consonância com as invariantes do objeto e da ação expostas pela orientação representada no quadro I, pois confere uma orientação de referência que possibilita um nível de transferência para uma classe de textos com ampla generalização de forma independente e com grau de consciência para a execução da ação.

Dessa forma, para fins desse estudo em função de se avaliar o nível de orientação da ação para leitura compreensiva de textos científicos de estudantes de pedagogia essa caracterização serviu de modelo para as análises.

\section{Metodologia do estudo}

O estudo retrata uma investigação realizada com 18 licenciandos do curso de Pedagogia da Universidade Federal do Rio Grande do Norte campi de Caicó/RN, na disciplina de metodologia do ensino das ciências, dos quais 11\% eram homens, 89\% mulheres e cuja média de idade era de 23,55 anos. Em relação à origem escolar dos participantes, 78\% são oriundos da escola pública enquanto $22 \%$ ingressaram na universidade advindos de escolas da rede privadas de ensino.

O estudo consistiu de uma intervenção exploratória com o objetivo de investigar o conhecimento profissional dos futuros professores de ciências sobre a orientação da ação relacionada à leitura crítica de textos de conteúdo científico e se delimitou sobre duas questões de estudo conforme mencionado anteriormente que se detinham nos seguintes aspectos: O que é a orientação da ação para leitura compreensiva de textos científicos em relação ao modelo do objeto (conceito) e ao modelo da ação (como se realiza)? Como você se orienta para realizar uma leitura compreensiva de um texto de conteúdo de ciências?

Para efeito dessa investigação, seguiu-se a lógica do experimento formativo de Vygotski, pois de acordo com Davidov (1988), possibilita compreender os aspectos psíquicos relacionados às funções psicológicas dos sujeitos acerca de um dado fenômeno, dessa maneira, em consonância com o fato de se pretender desvelar as relações psíquicas do pensamento conceitual dos sujeitos sobre a habilidade da leitura compreensiva, sem, no entanto ter como foco a formação da habilidade e sim o nível de orientação de cada sujeito em relação ao tema, considera-se oportuna a estratégia a partir da aplicação de prova pedagógica (em anexo), a qual foi aplicada e que consistia de um diagnóstico inicial para verificar qual a base orientadora da ação para ler textos de conteúdo de ciências com enfoque na caracterização do modelo do objeto e do modelo da ação, além de um texto de conteúdo 
científico para se observar a execução da ação, onde se solicitava que fosse feita uma leitura compreensiva do texto em dupla e a partir da ação se descrevesse o máximo de informações compreendidas no processo e se elencasse o passo a passo desenvolvido para a execução do procedimento de leitura.

A partir do resultado da prova pedagógica foi feita uma análise dos dados comparando o conteúdo das respostas dos alunos em relação ao modelo expresso pelo EBOCA em função da dimensão compreensiva sobre a ação que representa a orientação da ação inicial ou a base orientadora inicial dos estudantes em relação à leitura. Essa dimensão se referenciou a partir da lógica expressa pelo discurso que segundo Bardin (1977), evidenciam as relações, as representações, crenças, percepções e opiniões que são produtos das interpretações. Dessa forma, possibilita de acordo com os objetivos estabelecidos, compreender a partir dessas relações a orientação dos estudantes acerca da leitura compreensiva para textos de conteúdo científico.

A partir deste procedimento, se estabeleceu um agrupamento das respostas em nível de orientação comparado ao EBOCA, tanto em relação ao modelo do objeto como em relação ao sistema operacional com a seguinte proposta:

a) Em relação ao modelo do objeto: análise do conteúdo das respostas e sua categorização em relação a comparação ao EBOCA em função de uma orientação da ação que contivesse de maneira completa ou incompleta a presença do modelo do objeto relacionados aos eixos da temática, do contexto, da intencionalidade e da aplicação das informações do texto, categorizando as respostas em três níveis de orientação da ação, conforme o quadro abaixo.

Quadro II: Nível de orientação comparativo ao modelo do objeto presente no EBOCA

\begin{tabular}{|c|c|}
\hline $\begin{array}{c}\text { Nível I } \\
\text { (Orientação completa ou desejável) }\end{array}$ & $\begin{array}{l}\text { A orientação revela a presença completa da } \\
\text { invariante relacionadas ao modelo do objeto } \\
\text { em relação ao EBOCA, com presença no } \\
\text { diagnóstico de uma orientação compatível } \\
\text { com os eixos da temática, do contexto, da } \\
\text { intencionalidade e da aplicação das } \\
\text { informações }\end{array}$ \\
\hline $\begin{array}{c}\text { Nível II } \\
\text { (Orientação incompleta ou parcial) }\end{array}$ & $\begin{array}{l}\text { A orientação revela a presença incompleta da } \\
\text { invariante relacionadas ao modelo do objeto } \\
\text { em relação ao EBOCA, com presença no } \\
\text { diagnóstico de uma orientação compatível } \\
\text { com os eixos da temática, do contexto, da } \\
\text { intencionalidade e da aplicação das } \\
\text { informações }\end{array}$ \\
\hline $\begin{array}{c}\text { Nível III } \\
\text { (Não há orientação relacionada às invariantes) }\end{array}$ & $\begin{array}{l}\text { A orientação não revela consonância com o } \\
\text { modelo proposto pelo } E B O C A\end{array}$ \\
\hline
\end{tabular}

(Fonte: elaborado pelos autores)

b) Em relação ao modelo da ação: a partir da análise do conteúdo das respostas em função das operações envolvidas na orientação da ação se estabeleceu duas dimensões de 
leitura, em consonância com os conceitos estabelecidos por Cassany $(2006,2010)$ e em referência ao EBOCA, agrupando as respostas na dimensão decodificadora e na dimensão compreensiva em função da presença de operações específicas que foram categorizadas conforme o quadro abaixo:

Quadro III: Dimensão da orientação do modelo da ação em referência ao EBOCA

\begin{tabular}{|c|l|l|}
\hline $\begin{array}{c}\text { Dimensão decodificadora } \\
\text { do texto }\end{array}$ & $\begin{array}{l}\text { Relacionam no sistema } \\
\text { operacional as invariantes } \\
\text { das operações: O1, O2 e } \\
\text { O3 do EBOCA }\end{array}$ & $\begin{array}{l}\text { Revela orientação para uma leitura } \\
\text { decodificadora do texto sem a } \\
\text { orientação para inferências, } \\
\text { deduções e aplicações das } \\
\text { informações em contextos diversos }\end{array}$ \\
\hline $\begin{array}{c}\text { Dimensão compreensiva do } \\
\text { texto }\end{array}$ & $\begin{array}{l}\text { Relacionam no sistema } \\
\text { operacional as invariantes } \\
\text { das operações: O4, O5, } \\
\text { O6, O7, O8 e O9 do } \\
\text { EBOCA }\end{array}$ & $\begin{array}{l}\text { Revela orientação para uma leitura } \\
\text { compreensiva do texto a medida } \\
\text { que supera a decodificação e realiza } \\
\text { inferências, deduções e } \\
\text { extrapolações das informações para } \\
\text { outros contextos de aplicação }\end{array}$ \\
\hline
\end{tabular}

(Fonte: elaborado pelos autores)

Em função dessas categorias se fizeram as análises e tabulações dos dados contidos nas respostas, conforme mostrados nos resultados a seguir.

\section{Resultados e discussão}

Com o propósito de elucidar a primeira questão de estudo, a qual se centrava em torno da questão sobre o que é a orientação da ação para leitura compreensiva de textos científicos em relação ao modelo do objeto (conceito) e ao modelo da ação (como se realiza)? Foi realizada a tabulação dos dados em função dos níveis de orientação em relação ao EBOCA se traduzindo na seguinte tabela:

Tabela I: Categorização da orientação dos licenciandos em relação ao modelo do objeto

\begin{tabular}{cccc}
\hline Nível & Modelo do objeto & Número de estudantes & $\%$ \\
\hline I & $\begin{array}{c}\text { Apresentam orientação completa } \\
\text { em relação ao EBOCA }\end{array}$ & 03 & 16,66 \\
\hline III & $\begin{array}{c}\text { Apresentam orientação } \\
\text { incompleta em relação ao EBOCA }\end{array}$ & 04 & 22,22 \\
\hline & $\begin{array}{c}\text { A orientação não revela } \\
\text { consonância com o modelo } \\
\text { proposto pelo EBOCA }\end{array}$ & 11 & 61,12 \\
\hline
\end{tabular}

(Fonte: dados do estudo) 
Os dados demonstram que a ampla maioria dos estudantes não apresenta uma orientação completa para a leitura compreensiva de textos de ciências o que denota algumas possibilidades em relação ao contexto da investigação que merecem ser observados a fim de se possibilitarem reflexões e provocações em torno da formação de professores e do ensino das ciências.

Em relação à formação de professores de ciências os dados sugerem que há lacunas importantes a serem pensadas tendo como foco a inserção das habilidades linguísticocognitivas no rol dos conhecimentos profissionais para o ensino das ciências e para a orientação da ação no processo de aprendizagem dos estudantes em aulas de ciências, nessa perspectiva, tomando como suporte as evidências dos estudos trazidos pelo grupo de pesquisa Linguagem e Ensino de Ciências - LIEC, da Universidade Autônoma de Barcelona, o qual se consolida como uma referência neste contexto, em conformidade com as pesquisas de Sanmartí (2007, 2010, 2012); Bargalló (2005, 2012, 2017); Bargalló e Prat (2005), constatase a importância da inserção da leitura como uma habilidade para a educação científica e o ensino dos conteúdos de ciências descolando-se da visão equivocada porém presente nas concepções dos professores de que o ensino das linguagens é um recurso restrito ao ensino das línguas e ao processo de formação do leitor.

Nesse sentido Jorba (2000), García Barros e Martínez Losada (2014) e Sanmartí (2002) demonstram que a medida que se lê e se comunica em ciências o aprendizado conceitual e epistemológico do conteúdo científico se amplia, pois a aprendizagem científica passa pelo contexto da comunicação onde é imprescindível aprimorar as habilidades da leitura e o rol das capacidades que a envolvem como a argumentação, a explicação e a compreensão das informações.

Também nesse sentido, fazendo um paralelo da experiência internacional com os estudos desenvolvidos na base de pesquisas financiadas pelo CNPq, dentre as quais merece destaque o grupo de pesquisas que desenvolve estudos acerca desenvolvimento das habilidades linguístico-cognitivas no contexto da formação de professores na perspectiva enfoque histórico-cultural e da teoria de P. Ya. Galperin da UFRN, os quais já produziram uma série de constatações Nuñez, Ramalho e Uehara (2009), Nuñez e Ramalho (2011, 2015), Victor e Nuñez (2015), Pereira e Nuñez (2013, 2017), Ribeiro e Nuñez (2008); que demonstram que a fundamentação da orientação da ação e a formação das ações planejadas das ações mentais e dos conceitos como pressuposto epistemológico na formação das habilidades linguístico-cognitivas é uma via de desenvolvimento docente e de profissionalização da ação do professor pelo fato de aprimorar sua profissionalidade além de subsidiar as práticas docentes com embasamento no processo de aprendizagem das ciências.

Dessa forma, apesar de não poder se extrapolar os dados obtidos por essa investigação como uma realidade para a formação de pedagogos em geral, é possível, entretanto ponderar que estas lacunas estão presentes em boa parte dos profissionais a se constatar pelos índices de proficiência em ciências e em leitura dos dados dos exames nacionais e internacionais que ainda denotam hiatos na compreensão dos estudantes sobre temas que envolvem a interpretação das informações para a compreensão dos conceitos, como por exemplo, o histórico do PISA. Nesse sentido, investir em um processo de formação de professores que insira as habilidades linguístico-cognitivas no rol da profissionalidade docente 
bem como consolidar uma matriz teórica de referência, como por exemplo, a orientação da ação poderia contribuir muito no sentido de se reverter tais questões.

Para a segunda questão proposta para o estudo, que indagava ao estudante como você se orienta para realizar uma leitura compreensiva de um texto de conteúdo de ciências? Categorizou-se em função dos sistemas operacionais apresentados na orientação da ação de cada estudante e na avaliação do processo de leitura realizado pelos mesmos em duplas após a resolução do diagnóstico em duas dimensões de orientação: decodificadora e compreensiva, de acordo com a tabela a seguir:

Tabela Il: Categorização da orientação dos licenciandos em relação ao modelo da ação

\begin{tabular}{lccc}
\hline $\begin{array}{c}\text { Dimensão da } \\
\text { leitura }\end{array}$ & Modelo da ação & $\begin{array}{c}\text { Número de } \\
\text { estudantes }\end{array}$ & \% \\
\hline Decodificadora & $\begin{array}{c}\text { Apresenta uma orientação para uma leitura } \\
\text { decodificadora do texto sem orientação para } \\
\text { inferências, deduções e aplicações das } \\
\text { informações em contextos diversos }\end{array}$ & 06 & 33,33 \\
\hline Compreensiva & $\begin{array}{c}\text { Apresenta uma orientação para uma leitura } \\
\text { compreensiva do texto a medida que supera a } \\
\text { decodificação e realiza inferências, deduções e } \\
\text { extrapolações das informações para outros contextos } \\
\text { de aplicação }\end{array}$ & 12 & 66,67 \\
\hline
\end{tabular}

(Fonte: dados do estudo)

Em relação ao modelo da ação para a orientação compreensiva da leitura de textos de ciências os dados se aproximam dos que foram obtidos para o modelo do objeto o que denota uma correlação entre a compreensão conceitual e operacional dos estudantes em função da habilidade pesquisada, tal constatação é importante, pois à luz do experimento formativo está condizente que um modelo divergente em relação ao modelo do objeto não poderia resultar em uma dimensão diferente em termos operacionais, o que reforça a ideia de que não se divide a teoria de seu fazer, ou mesmo, que não há dualidade entra a concepção e a ação.

Neste sentido, analisando no campo da didática se reforça a ideia que para a formação das habilidades no ensino das ciências a partir do domínio de uma habilidade geral é necessário um planejamento docente e experiências formativas que integrem o sentido prático e psíquico ao processo de assimilação. Dessa maneira, isto só se viabiliza a partir de estratégias que integrem a orientação e a execução de modo a garantir um sistema de operações da ação estreitamente ligado ao modelo do objeto, em outras palavras, como destacam Nuñez e Ramalho (2015, p. 4) "para se formar o sistema de operações da ação, precisa-se de uma orientação adequada em estreita união com os conceitos".

No caso específico da leitura compreensiva para textos de conteúdo de ciências, a adoção integral de conteúdos didáticos que integrem nas tarefas a invariante conceitual e operacional da ação incorporando às sequências didáticas o subsistema orientador da atividade, dessa maneira, o professor das ciências deve incorporar às aulas de ciências a orientação da ação como critério para avaliação da aprendizagem e nesse percurso elaborar 
esquemas de bases orientadoras completas (EBOCA's) a partir das caracterizações das invariantes essenciais à assimilação dos conceitos e habilidades relacionadas ao ensino de seus conteúdos.

Outra estratégia didática importante consiste em possibilitar práticas de aprendizagem colaborativa, em conformidade com a lógica das zonas de desenvolvimento próximo de Vygotski, pois, de acordo com sua leitura na perspectiva de uma didática desenvolvimental, possibilita como defende Lopes e Puentes (2016), estimular o desenvolvimento potencial dos estudantes, pois permite que colaborativamente haja a mediatização interpsíquica que auxilia na formação das ações mentais intrapsíquicas.

\section{Conclusões}

Um estudo dessa natureza não tem necessariamente a pretensão de concluir em termos do absoluto ou no sentido de extrapolar inferências universais, ao contrário, processos de formação profissional e o contexto da aprendizagem estão inseridos em variáveis diversas que uma investigação dessa natureza não alcança, no entanto, apesar dessas limitações peculiares o estudo congrega muitas possibilidades de leituras que associadas às evidências que trazem podem sugerir novas demandas e percursos para se pensar um processo de educação científica mais ampla e eficiente do ponto de vista da formação dos pedagogos, das estratégias didáticas e da epistemologia da aprendizagem a partir do conceito de orientação da ação.

Nessa perspectiva o estudo confirma a necessidade premente de se pensar em um processo de formação de professores de ciências - e aqui reside especial atenção ao pedagogo, pois é o profissional que primeiro inicia esse processo da educação básica - que envolva os aspectos relacionados à formação de habilidades de leitura como premissa para ensinar conteúdos, conceitos e informações das ciências, além de demais habilidades linguístico-cognitivas que tenham relação com a leitura compreensiva, como a argumentação, a descrição, a explicação, a inferência e a justificativa, dentre outros, a fim de possibilitar para os estudantes uma educação científica mais compatível com as necessidades atuais.

Através da investigação observa-se que a leitura compreensiva é uma porta para se inserir práticas de ensino de ciências e que o texto científico envolve muito mais que informações sobre ciências e conteúdos curriculares específicos, assim, a leitura deve ser um ponto de partida para encaminhar uma base orientadora promotora da educação para a cidadania.

\section{Referências}

Bardln, L. (1977). Análise de conteúdo. Lisboa: edições, 70, 225.

Bargalló, C. M., \& Prat, À. (2005). Leer en clase de ciencias.Enseñanza de las ciencias: revista de investigación y experiencias didácticas, 23(3), 431-440.

Brasil (1996). N. 9.394 de 20 de dezembro de 1996.Estabelece as Diretrizes e Bases da educação Nacional. Diário Oficial da República Federativa do Brasil, Brasília, DF,23. 
Brasil (2006) Ministério da Educação, \& Conselho Nacional de Educação. (2006). Resolução CNE/CP n 1, de 15 de maio de 2006. Institui Diretrizes Curriculares Nacionais para o Curso de Graduação em Pedagogia, licenciatura. Diário Oficial [da República Federativa do Brasil].

Cassany, D. (2006). Tras las líneas: sobre la lectura contemporánea.

Cassany, D. (2010). De la alfabetización a la literacidad crítica. Recuperado de http://revistadixit. ucu. edu. uy. dixit.(S. Caballero, Entrevistador).

Davidov, V. (1988). La enseñanza escolar y el desarrollo psíquico. Moscú: Editorial Progreso, 174.

de Carvalho, A. M. P., \& Gil-Pérez, D. (2003). Formação de professores de ciências: tendências e inovações. Cortez.

dos SANTOS, A. A. A., Vendramini, C. M. M., Suehiro, A. C. B., \& dos dos Santos, L. A. D. (2006). Leitura compreensiva e utilização de estratégias de aprendizagem em alunos de Psicologia. Estudos de Psicologia, 23(1), 83-91.

Galperin, P. Y. (1965). La dirección del proceso de aprendizaje. Luis Quintanar-Rojas (2001). La formación de las funciones psicológicas durante el desarrollo del niño, capítulo,1.

Galperin, P. Y. (1987). Los tipos fundamentales de aprendizaje. Selección de lecturas de psicología pedagógica. La Habana: ENPES, 53-61.

Galperin, P. Y., \& Bustamante, A. (1979). Introducción a la psicología: un enfoque dialéctico. Pablo del Rio.

García Barros, S., \& Martínez Losada, C. (2014). La importancia de las habilidades cognitivolingüísticas asociadas al estudio de la Astronomía desde la perspectiva del profesorado. Enseñanza de las Ciencias, 32(1), 0179-197.

Jorba, J., Gómez, I., \& Prat, À. (Eds.). (2000). Hablar y escribir para aprender: uso de la lengua en situación de enseñanza-aprendizaje desde las áreas curriculares. Editorial Síntesis.

Jorge, A. S., Bargalló, C. M., \& Puig, N. S. (2006). Cómo promover distintos niveles de lectura de los textos deficiencias. Revista Electrónica de Enseñanza de las ciencias, 5(2), 290-303.

Koch, I. G. V. (2018). Desvendando os segredos do texto. Cortez Editora.

Leontiev, A. N. (1978). Actividad, consciencia y personalidad.Buenos Aires.

Leontiev, A. N., \& Duarte, M. D. (1978). O desenvolvimento do psiquismo.

Núñez, I. B., \& Ramalho, B. L. (2015). (2008). A profissionalização da docência: um olhar a partir da representação de professoras do ensino fundamental. Revista Iberoamericana de educación, 9 (46), 1-15.

Núñez, I. B., \& Ramalho, B. L. (2015). Conhecimento profissional para ensinar a explicar processos e fenômenos nas aulas de Química. Revista Educação em Questão, 52(38), 243-268.

PISA, O. (2000). Measuring student knowledge and skills. The PISA Assessment of Reading. Mathematical and Scientificliteracy. 
Sanmartí, N. (2007). Hablar, leer y escribir para aprender ciencia. La competencia en comunicación lingüística en las áreas del currículo, 103-128.

Talizina, N. (1998). La enseñanza según la Teoría General de la Dirección. Psicología de la Enseñanza. La Habana.

Talizina, N.. (2000). Manual de psicología pedagógica. UASLP.

Victor, C. M. B. (2015). O conhecimento de licenciados em química para ensinar a ler de forma compreensiva os textos complementares dos livros de química (Master's thesis, Universidade Federal do Rio Grande do Norte).

Vygotsky, L. S. (1993). Obras escogidas: problemas de psicología general. Visor. 


\section{Anexo: Pesquisa sobre habilidades linguístico-cognitivas e ensino das Ciências}

Nome (somente iniciais): Idade: Ingressou na Universidade:

Cursou a educação básica: Escola pública ( ) Pública Escola Privada ( )

Orientação: Responda com o máximo de detalhamento sem a preocupação de estar sendo avaliado, os dados dessa prova pedagógica serão objeto de uma pesquisa acadêmica onde são resguardadas as identidades e sua participação é voluntária.

\section{Diagnóstico inicial}

A) O que é a orientação da ação para leitura compreensiva de textos científicos?

B) Como você se orienta para realizar uma leitura compreensiva de um texto de conteúdo de ciências? (passo a passo)

C) Faça uma leitura compreensiva do texto que segue, registre o máximo de informações sobre o que você fez durante o processo da leitura e ao final, responda as perguntas do texto.

\section{OTEMPO \\ SAÚDE E CIÊNCIA PESQUISA}

\section{UFMG cria espuma que absorve agrotóxico da água e dos alimentos}

Esponja identifica e extrai quatro pesticidas sem afetar nutrientes

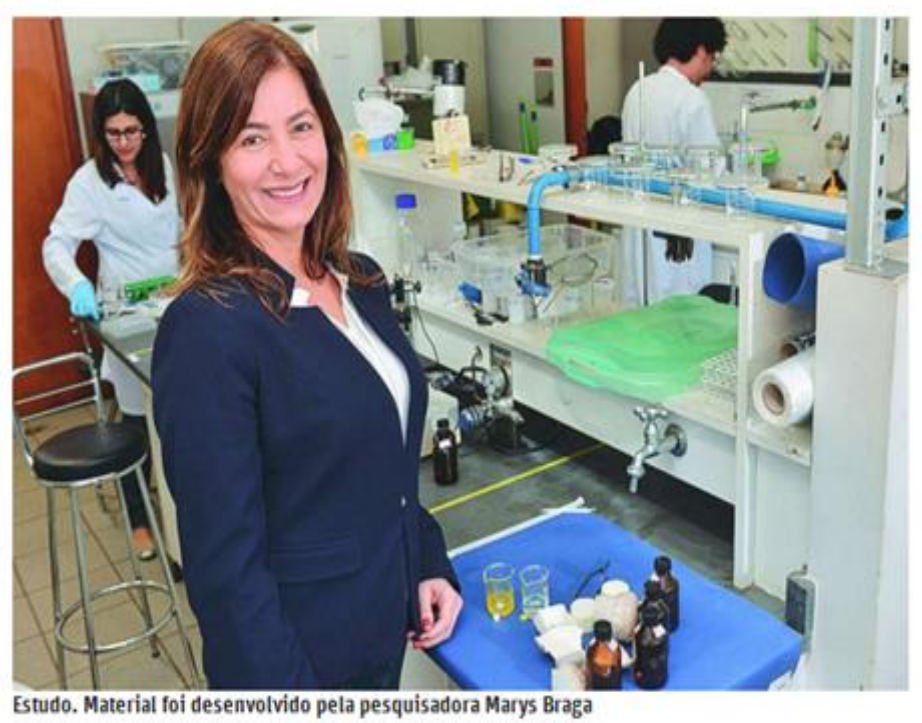

O plástico é um dos materiais que pertence a família dos polímeros e, provavelmente, o mais popular. O seu uso, no entanto, vem sendo questionado em relação aos malefícios gerados ao ambiente. Mas, após estudar alternativas sustentáveis para esse material, pesquisadores da Universidade Federal de Minas Gerais (UFMG), conseguiram desenvolver uma espuma de poliuretano capaz de detectar e absorver herbicidas da água e dos alimentos. O material foi produzido pelos próprios pesquisadores, usando como matéria-prima resíduos da indústria petroquímica (catalisador de petróleo) e componentes naturais, como óleo de mamona, conforme explica a engenheira química e pesquisadora pósdoutoranda da UFMG Marys Lene Braga.

Essa composição inédita deu origem a um material com "grupos químicos que facilitam a interação com o pesticida", ou seja, com propriedades para que a espuma identifique apenas os agrotóxicos. Foram feitos testes com quatro pesticidas mais frequentes (organoclorados, clorobenzeno, atrazina e trifluralin). Exames complementares também foram aplicados para investigar se a espuma não extraía também os nutrientes dos alimentos, e ambos os resultados foram satisfatórios. Ou seja, a espuma conseguiu retirar os agrotóxicos dos alimentos sem comprometer suas propriedades nutricionais. A eficiência é em torno de $70 \%$ da espuma com resíduo e com o resíduo puro chega a 95\% de remoção do pesticida", explica a pesquisadora.

Após a leitura compreensiva, responda:

a) $O$ texto defende o uso de agrotóxicos na produção de alimentos? Justifique.

b) Pela leitura é possível concluir que a intencionalidade do texto é justificar o uso de agrotóxicos na produção de alimentos? Justifique.

c) O texto mostra uma pesquisa que descreve uma solução para o uso de agrotóxicos na agricultura. Destaque do texto uma passagem que justifique sua resposta.

d) Que conclusões se tiram após a leitura do texto? 